\title{
Results of the First Mammography Screening Projects in Germany from a Histopathological Viewpoint
}

\author{
Ulrich Bonk $^{\mathrm{a}} \quad$ Gabriela Gohla $^{\mathrm{a}}$ Sylvia Heumann ${ }^{\mathrm{a}} \quad$ Werner Böcker ${ }^{\mathrm{b}}$ \\ a Zentrum für Pathologie des Klinikverbundes, Bremen, \\ b Institut für Pathologie Universität Münster, Germany
}

Key Words

Mammography · Biopsy · Pathology · Screening

\section{Summary}

Background: The aim of this study was to review the role of the pathologist in mammography screening. Patients and Methods: The first German mammography screening project was undertaken in Bremen in June 2001. Women between the ages of 50 and 69 were offered mammographic assessment. Suspicious findings were followed up by a stereotactic core biopsy or vacuum-assisted core biopsy. The tissue was examined at the Department of Pathology in Bremen as well as at the Section of Breast Pathology at the University Münster. Each case was discussed in a multidisciplinary board. The core biopsies were classified according to the 5-point scale of the internationial guidelines. Results: Biopsies were obtained from 402 women within the first 2 years of the screening project. Of these, $47 \%$ were assigned to group B5 (malignant), 44\% were categorized in group B2 (benign) while 1\% was classified in group B1 (regular breast tissue, unsatisfactory) and $8 \%$ were assigned to the group B3/B4 (lesion of uncertain malignant potential / suspicious for malignancy). The discrepancies in $10 \%$ of the cases centered on papillary lesions, flat epithelial atypia (FEA) and atypical ductal hyperplasia (ADH). Conclusion: In clearly defined lesions the agreement of the histological findings of independent pathologists is very high. In unclear lesions it should be raised. In addition, close cooperation between clinicians, radiologists and pathologists is critical.

\author{
Schlüsselwörter \\ Mammographie · Biopsie · Pathologie · Screening
}

\section{Zusammenfassung}

Hintergrund: Das Ziel dieser Untersuchung war es, die Rolle des Pathologen in einem Mammographie-Screening-Projekt zu überprüfen. Patientinnen und Methoden: 2001 begann das erste deutsche Mammographie-Screeningprojekt in Bremen. Alle Frauen dort zwischen 50 und 69 Jahren wurden zu einer Mammographie eingeladen. Auffällige Befunde wurden mittels stereotaktischer Hohlnadelbiopsie abgeklärt. Das Gewebe wurde in der Pathologie in Bremen sowie im Referenzzentrum für Mammapathologie der Universität Münster begutachtet und im Rahmen eines multidisziplinären Assessments diskutiert. Die Gewebsproben wurden nach der 5-Punkte-Skala (BKlassifikation) analog zu den Leitlinien der Europäischen Union für das Brustkrebsscreening eingestuft. Ergebnisse: In den ersten 2 Jahren des Screening-Projekts wurden von 402 Frauen Stanz- oder Vakuumsaugbiopsien entnommen. 47\% der Fälle wurden der Gruppe B5 (maligne) zugeordnet, $44 \%$ der Befunde wurden in die Kategorie B2 (gutartig) eingestuft, 1\% als B1 (reguläres Mammagewebe) und 8\% der Befunde wurden als B3/B4 eingestuft (unsichere Dignität, malignitätsverdächtig). In 90\% der Fälle bestand eine Übereinstimmung bei der BKlassifikation zwischen der hiesigen Pathologie und der Referenzpathologie im offenen Konsensus. In 10\% der Fälle kam es zu Diskrepanzen, diese betrafen die Bewertung papillärer Läsionen, flacher Epithelatypien und atypischer duktaler Hyperplasien. Schlussfolgerung: Die Übereinstimmung der Diagnosen ist bei klar definierten Läsionen sehr hoch und sollte bei nicht klar definierten Läsionen erhöht werden.

\begin{tabular}{|c|c|}
\hline KARGER & (C) 2006 S. Karger GmbH, Freiburg \\
\hline $\begin{array}{l}\text { Fax +49 } 7614520714 \\
\text { E-mail Information@Karger.de } \\
\text { www.karger.com }\end{array}$ & $\begin{array}{l}\text { Accessible online at: } \\
\text { www.karger.com/brc }\end{array}$ \\
\hline
\end{tabular}

Prof. Dr. Ulrich Bonk 


\section{Introduction}

Breast cancer is one of the most frequently diagnosed malignancies in women in the Western World, including Germany. Extensive mammographic screening has been introduced in several countries within Europe and America in the past several decades. The ability to detect non-palpable, minimally invasive carcinoma as well as ductal carcinoma in situ (DCIS) has largely contributed to a drop in mortality [1]. Several studies confirm the effectiveness of screening. For example, through screening a drop in mortality up to $40 \%$ was achieved in Scandinavian countries and in the USA [1]. For several years, introduction of mammographic screening in Germany has been controversial. It had been assumed that voluntary screening provides a sufficient health benefit that could not be significantly improved by a routine screening program.

In March 2001, the first German pilot Mammography Screening Project was launched in Bremen and initially planned to end in March 2003. Because of the clear benefit afforded by this program, the project was continued beyond 2003 . Presently, an extensive mammography screening has been introduced in Germany.

The approach in the histopathologic assessment of breast lesions has changed significantly since the introduction of mammographic screening. Clinicians and pathologists are now confronted more frequently with non-visible or nonpalpable lesions. Morphologic assessment is much more difficult in small core biopsies. This applies in particular to subtle lesions such as atypical ductal hyperplasia and flat epithelial atypia. Papillary epithelial proliferations are also a special problem. Given the possible surgical consequences, the histopathological diagnosis should be given with a high degree of reliability. The practice of reviewing the diagnoses made at the Department of Pathology in Bremen by a second pathologist with expertise in breast pathology is unique to this study and is not routinely applied in Germany.

\section{Patients and Methods}

All women in Bremen between the ages of 50 and 69 years were offered mammography. In the first 24 months, radiologically suspicious areas were followed up by means of a core biopsy. In cases of well demarcated lesions, 2-3 core biopsies were removed with stereotactic guidance. Approximately 10 biopsies were removed in cases of suspicious microcalcification or diffuse processes. In the case of an unsatisfactory core biopsy result, up to 30 vacuum-assisted core biopsies were taken. A specimen radiograph was taken and any suspicious calcifications were marked by the radiologist. These biopsies were prepared to ensure that the suspicious lesions were adequately sampled. Regular core biopsies were submitted in separate cassettes. Tissue was fixed in $10 \%$ buffered formalin and rapidly processed in $3 \mathrm{~h}$. From each paraffin block, 6 serial sections were cut and examined after conventional hematoxylin-eosin staining. In some cases, additional immunohisto-
Table 1. Diagnoses in Bremen and Münster on the basis of categorization following the B-classification

Table 2. Diagnosis of benign mammary changes (B2)

chemical studies were performed with the Ventana benchmark 'Immunostainer' (Ventana Medical Systems, Inc., Tucson, AZ, USA) using the ABC detection method.

For the assessment of possible stromal invasion in cases of DCIS or lesions like sclerosing adenosis or radial scar, a myoepithelial marker (actin) was used. To distinguish between lobular carcinoma in situ and DCIS, e-Cadherin immunostain was used. The use of high molecular weight keratin CK5/6 was helpful in the assessment of DCIS, atypical ductal hyperplasia (ADH) and usual ductal hyerplasia. An inter-disciplinary conference was held the following day during which the histopathological findings were presented and management was discussed with the radiologists and clinicians or surgeons.

The initial pathologic assessment at the Department of Pathology in Bremen was made by 2 staff pathologists with experience in breast pathology. Results were documented using a standard form according to the European Union (EU) Guidelines in Mammography Screening [2]. This 5point score largely corresponds to the B-classification that was developed by the NHSBS in Great Britain. Excisional biopsies were processed in accordance with the guidelines of the EU for breast cancer screening. Normal mammary tissue or fat tissue (usually insufficient material) is classified as category 1 . Benign breast changes or benign tumors are classified as category 2. Category 3 is designated for lesions of uncertain malignant potential such as papilloma, flat epithelial atypia (FEA), ADH, radial scars or complex sclerosing lesions. These lesions may be associated with carcinoma or with an increased risk of breast cancer [3]. Carcinoma lobulare in situ also was designated as category B3; usually this is an incidental finding. Category B4 specifies lesions that are presumed to be an in situ or invasive carcinoma but cannot be stated as such definitively for technical reasons. Category B5 indicates a clear-cut malignant process (non-invasive DCIS or invasive malignancy). Cases assigned to category B4 or B5 are usually managed surgically. In case of category B3, further surgical procedures are performed with due consideration for the histological, clinical and radiological finding.

The completed documentation form was sent along with the slides to the breast pathology subdivision of the department of pathology at the University Münster (Head: Prof. Dr. W. Böcker). There, the slides were reviewed. In case of discrepancies, further procedures were implemented on an individual basis. 
Table 3. Diagnoses of malignant mammary lesions (B5)

\begin{tabular}{lc}
\hline Diagnosis & $\mathrm{n}(\%)$ \\
\hline Invasive ductal carcinoma & $90(48)$ \\
Invasive lobular carcinoma & $27(15)$ \\
Ductal carcinoma in situ (DCIS) & $35(19)$ \\
Invasive carcinoma mixed types & $14(7)$ \\
Invasive tubular mammary & \\
$\quad$ carcinoma & $18(10)$ \\
Other types & $2(1)$ \\
Total & $186(100)$ \\
\hline
\end{tabular}

Table 4. Definitive diagnosis in the excision biopsy in case of unclear findings B3, B4 of the department in core biopsy of pathology of Bremen

\begin{tabular}{ll}
\hline Core biopsy & Excision biopsy \\
\hline B3 $(\mathrm{n}=30)$ & 22 evaluable cases \\
& 2 adenosis \\
& 2 ductal hyperplasia \\
& 1 radial scar \\
& 1 fibro-adenoma \\
& 7 solitary papilloma \\
& 3 papillomatosis \\
& 3 DCIS \\
& 3 invasive ductal Ca \\
& 4 evaluable cases \\
& 1 papillomatosis \\
& 2 DCIS \\
& 1 DCIS and invasive \\
& carcinoma \\
\hline
\end{tabular}

Table 6. Final diagnosis in excision biopsy in specimens with diagnosis DCIS (B5) made in core biopsy $(\mathrm{n}=34)$

Table 5. Definitive diagnosis in excision biopsy in case of deviating findings in core biopsy (B3, B4) in Münster and Bremen

\begin{tabular}{ll}
$\begin{array}{l}\text { Core biopsy, deviation } \\
\text { from Bremen }\end{array}$ & Excision biopsy \\
\hline B3 $(\mathrm{n}=18)$ & 6 evaluable cases \\
& 1 adenosis \\
& 1 ductal hyperplasia \\
& 1 fibro-adenoma \\
& 1 solitary papilloma \\
& 1 papillomatosis \\
& 1 DCIS \\
& 2 evaluable cases \\
& 1 lymphocytic \\
B4 $(\mathrm{n}=3)$ & mastitis \\
& 1 fibroadenoma
\end{tabular}

\begin{tabular}{lrl}
\hline Tumor stage & $\mathrm{n}$ & $\begin{array}{l}\text { Lymph node } \\
\text { metastases }\end{array}$ \\
\hline ptis & 26 & n.a. \\
pT1a & 2 & 0 \\
pT1b & 4 & 0 \\
pT1c & 1 & 1 \\
pT2 & 1 & 1 \\
\hline
\end{tabular}

Tables 1 and 4 indicate that findings were more often categorized into groups B3 and B4 in the department of pathology of Münster. In the beginning of the screening it was also not clear how to properly categorize lesions like flat epithelial atypia (FEA) or papillary lesions and they were classified as B2. The diagnoses of both institutes were not concordant in 40 cases $(10 \%)$. This had to do with changes like flat epithelial atypia and atypical epithelial hyperplasia as well as the assessment of papillary changes. Histological verification through excisional biopsy should always be carried out in changes that were categorized as B4. Table 5 shows that evidence of carcinoma could be found in the excisional biopsy. Some patients were lost in follow-up.

The results of category B2 (benign lesions) and B5 (malignant lesions) obtained from the department of pathology of Bremen are presented in tables 2 and 3 . Tables 4 and 5 show the results of the core biopsies in comparison to the final results in the excisional biopsy in the departments of pathology of Bremen and Münster (in case of discrepant findings). The final tumor stage of the invasive and non-invasive carcinomas that were categorized as B5 are presented in tables 6 and 7 . Interobserver disagreement in Bremen and Münster was noted in 40 cases (10\%). The results are summarized in table 8 .

Benign changes that were observed most frequently were fibroadenoma, fibrocystic changes with or without ductal epithelial hyperplasia as well as sclerosing adenosis. In these cases, radiologically suspicious groups of calcification warranted the biopsy. In malignant findings, invasive ductal carcinoma was most frequently diagnosed. The second most frequent diagnosis was invasive lobular carcinoma.

\section{Discussion}

The agreement of the histological findings of different, independent pathologists is very high in cases of clearly defined lesions. However, as the review of the specimens was not blinded, the results might be somewhat biased. The review was performed on the basis of a consultation as it is more frequently performed e.g. in Great Britain, the United States and Canada. In these series no false positive results were found and reproducibility between the independent pathologists was $100 \%$. This is a very important finding as a high level of reliability of the histopathological diagnosis in general and especially in mammography screening is necessary. The criteria for success of a mammography screening in accordance with the guide- 
Table 7. Final tumor stage of the invasive carcinomas that were presurgically diagnosed in core biopsies $(n=147)$

\begin{tabular}{lcl}
\hline Final tumor stage & $\mathrm{n}(\%)$ & $\begin{array}{l}\text { Lymph node metastases, } \\
\mathrm{n}(\%)\end{array}$ \\
\hline pT1a and pT1b $(0.1-1 \mathrm{~cm})$ & $53(36)$ & $3(5.6)$ \\
pT1c $(1.1-2 \mathrm{~cm})$ & $59(40)$ & $16(27)$ \\
pT2 $(2.1-5 \mathrm{~cm})$ & $28(19)$ & $12(43)$ \\
pT3 $(>5 \mathrm{~cm})$ & $5(3)$ & $5(100)$ \\
no more trace of carcinoma & $1(1)$ & 0 \\
no data & $1(1)$ & n.a. \\
\hline
\end{tabular}

lines of the European Commission in which a relatively high share of small and non-invasive carcinomas is required, were met [3].

Compared with the data of the year 1999 from the Cancer Registry of Bremen [5], which already shows a large number of small tumors and non-invasive carcinomas, the number of small tumors and DCIS could be clearly increased. More recent research, however, indicates that genetic characteristics of the tumor cells probably have more influence on growth behavior than the size of the tumor [6].

Carcinomas with low metastatic risk such as tubular carcinomas could be diagnosed more frequently. In 8 cases in which a non-invasive ductal carcinoma was diagnosed with core biopsy, an invasive carcinoma was found in the excisional biopsy. In these cases the invasive tumor had not been present in the core biopsy, or extensive DCIS with very small foci of invasive cancer was found in the excisional biopsy. False negative results in the core biopsies were due to sampling error. These results clearly highlight the significance of the interdisciplinary conference for the exact assessment of findings.

Difficulties are encountered in the assessment of precancerous lesions (also called indicator lesions) like FEA and ADH which cannot be precisely circumscribed. These changes of the category B3 were partially interpreted differently in Bremen and Münster. Especially in the beginning of the screening project the term FEA was not used as the new WHO classification had not yet been published. There was also uncertainty about the diagnostic criteria to be used in these lesions and the category they should be assigned to.

There are no further uniform procedures on how to proceed in punch biopsy in changes of the category B3. Reference sources reveal that invasive cancer or DCIS can be found in excisional biopsies while the core biopsy only shows changes like ADH. Meanwhile the European working group of pathologists has proposed to use the term 'atypical ductal proliferation' instead of the term ADH in the assessment of core biopsies and to reserve the term $\mathrm{ADH}$ only for excisional biopsies. As the diagnosis of DCIS and ADH is not only based on morphology but also on size, further surgical intervention is recommended [7] in accordance with the European Guidelines for Mammography Screening and other sources.
Table 8. Diverging B-classification of the departments of pathology of Bremen and Münster

\begin{tabular}{llr}
\hline Classification & \multicolumn{2}{c}{$\mathrm{n}$} \\
\cline { 1 - 2 } Bremen & Münster & 3 \\
\hline B2 fibrocystic mastopathia & B1 normal tissue & \\
B2 ductal hyperplasia & B3 flat epithelial atypia (FEA), & \\
& atypical ductal hyperplasia (ADH) & 18 \\
B2 lymphocytic mastitis & B4 presumed lymphoma, ADH & 3 \\
B3 ADH, papillary lesion & B2 ductal hyperplasia, apocrine & \\
B3 ADH, papillary lesion & metaplasia & 8 \\
B4 ADH & B3 FEA & 3 \\
B4 presumed DCIS & B3 ductal hyperplasia & 1 \\
B5 DCIS & B4 carcinoma lobular in situ (CLIS) & 1 \\
\hline
\end{tabular}

Total

The categorization of minimal findings like FEA and $\mathrm{ADH}$ is a general problem that is encountered not only in the field of mammary pathology but is also discussed in detail in numerous publications [8-11]. The circumscription of low-grade DCIS and ADH may prove very difficult, particularly in core biopsies [7]. The diagnosis of FEA is even more difficult [12]. Here too, there was poor concordance between independent breast pathologists.

A comparison of the diagnoses of $\mathrm{ADH}$ and FEA that were performed in the department of pathology in Bremen in the first and second year of screening reveals that these diagnoses were more frequent during the second year. Contrarily, the rate of these diagnoses dropped in Münster in such a way that there was some degree of convergence.

From the viewpoint of molecular genetics, FEA like $\mathrm{ADH}$ constitutes a neoplasia. ADH is particularly regarded as an indicator lesion for the increased risk of breast cancer as opposed to standard criteria $[13,14]$. In the investigations, however, only a few cases were evaluated retrospectively and the poor reproducibility of the findings was not taken into consideration $[15,7]$.

In the new tumor classification released by the WHO [16, 17], changes like FEA and ADH together with DCIS are classified very much like in cervical pathology, as ductal intra-epithelial neoplasia (DIN) with low, intermediate or high risk. As the term 'carcinoma' is omitted, this classification is expected to avoid excessive therapy on very early neoplastic changes. Recommendations on further therapies as proposed by Tavassoli [10] will surely be of use in this case in order to create a standard approach to these lesions. Most probably reproducibility will not be increased through this classification. Management of patients in whom FEA and ADH are detected in mammography screening without further focal findings may prove difficult and possibly means life-long uncertainty for the women. It therefore appears reasonable to conduct larger prospective surveys on early changes of the breast. 
It should be emphasized that these changes are rare and correspond to $7 \%$ and $10 \%$ of the specimens examined in Bremen and Münster, respectively. Before initiation of mammography screening, FEA was not diagnosed in any of the specimens examined in Bremen and ADH was diagnosed in less than $1 \%$ of incoming mammary biopsies. To obtain a high number of meaningful examinations, a pan-European cooperation therefore appears reasonable to us.

Since critical findings are often made in mammography screening and evaluation is more difficult in a small core biopsy than in an excision biopsy, the pathologists require an intensified training. A major problem is that the border of the area of minimal changes often is hard to identify, which renders reproducibility of the diagnosis difficult. There are now attempts to define early changes like FEA more clearly [18] but interobserver agreement is still poor. However, it can be increased by training [18].
In the face of the present observations it appears reasonable to divide the intra-epithelial neoplasia into 3 groups: changes with low (FEA), intermediate (ADH, low-grade DCIS) and high risk (intermediate and high-grade DCIS). This will, of course, clearly lead to a higher level of concordance in diagnosis and simplify the decision on further diagnostic and therapeutic decisions.

A simpler and safe classification will also serve to minimize the uncertainty of the patient and enhance understanding. This is particularly important in the screening of asymptomatic or healthy women.

\section{Acknowledgement}

The content of this article was published in German at www.aerzteblatt.de/aufsaetze/0501/ and translated with kind permission of Deutsches Ärzteblatt online.

\section{References}

1 Winchester DP, Sener SF: Impact of screening mammography on breast cancer treatment and mortality. Breast Dis 2003;13:323-325.

2 Quality assurance guidelines for pathology in mammography screening, open biopsy and resection specimens; in European Quality Assurance in Mammography Screening (ed 3). Office for Official Publications of the European Communities, 2001, pp 173-207.

3 Rosai SJ, Conolly JL, Tavassoli FA et al.: Interobserver reproducibility in the diagnosis of ductal proliferative lesions using standardized criteria Am J Surg Pathol 1992;16:1133-1143.

4 Quality assurance guidelines for pathology in mammography screening, epidemiological guidelines for quality assurance in breast cancer screening in european quality assurance; in Mammography Screening (ed 3). Office for Official Publications of the European Communities, 2001, pp 15-66.

5 Page DL, Rogers LW: Combined histologic and cytologic criteria for the diagnosis of mammary atypical ductal hyperplasia. Hum Pathol 1992;23 1095-1097.

6 Van de Vijver MJ, Yudong D, van't Veer LJ et al.: A gene-expression signature as a predictor of survival in breast cancer. N Engl J Med 2002;347: 1999-2009.
7 Jacobs TW, Conolly JL, Schmitt SJ: Non-malignant lesions in breast core needle biopsies: to excise or not to excise? Am J Surg Pathol 2002;26:1095-1110.

8 Quality assurance guidelines for pathology in mammography screening, epidemiological guidelines for quality assurance in breast cancer screening; in European Quality Assurance in Mammography Screening (ed 3). Office for Official Publications of the European Communities, 2001, pp 15-66.

9 Shaaban AM, Sloane JP, West CR et al.: Histopathologic types of benign breast lesions and the risk of breast cancer: case-control study. Am J Surg Pathol 2002;26:421-430.

10 Tavassoli FA: Ductal intaepithelial neoplasia of the breast. Virchows Arch 2001;438:221-227.

11 Sanders ME, Schuyler PA, Dupont WD, Page DL: The natural history of low grade ductal carcinoma in situ of the women treated by biopsy only revealed over 30 years of long-term follow-up. Cancer 2005;103:2481-2484

12 Sloane JP, Ellman R, Anderson TJ et al.: Consistency of histopathological reporting of breast lesions detected by screening: Findings of the UK National External Quality Assessment (EQA) Scheme. Eur J Cancer 1994;30A:1414-1419.
13 Ely KA, Carter BA, Jensen RA, et al.: Core biopsy of the breast with atypical hyperplasia: a probabilistic approach to reporting. Am J Surg Pathol 2001;25:1017-1021.

14 Schnitt SJ: The diagnosis and management of preinvasive breast disease: flat epithelial atypia - classification, pathologic features and clinical significance. Breast Cancer Res 2003;5:236-238.

15 Marquardt U, Giersiepen K, Eberle A: Annual report of the cancer register of the City of Bremen, incidence and mortality in the year 1999, July 2002. Available at: http://www.krebsregister.bremen.de

16 Dupont WD, Paarl FF, Hartmann WH, et al: Breast cancer risk associated with proliferative breast disease and atypical hyperplasia. Cancer 1993;71:1258-1265.

17 Tavassoli FA, Devilee P: WHO Classification of Tumours: Pathology and Genetics of Tumours of the Breast and Female Genital Organs. IARC Press, 2003, pp 63-73.

18 O'Malley FP, Mohsin SK, Bavde S, Bose S, Collins LC, Ennis M, Kleer CG, Pinder SE, Schnitt SJ: Interobserver reproducibility in the diagnosis of flat epithelial atypia of the breast. Mod Path 2006; 19:172-179. 